\title{
Ethnic Renewal: Identity Formations among Current Generation Hindu Migrants of Punjab of 1947 Partition
}

\author{
Shaifali Arora ${ }^{1} \&$ Nirmala Menon ${ }^{2}$ \\ ${ }^{1}$ PhD scholar, Discipline of English, Digital Humanities and Publishing Studies Research \\ Group, School of Humanities and Social Sciences, Indian Institute of Technology Indore. \\ ORCID id: oooo-0002-3547-7162. Email: arora.shaifali16@gmail.com \\ ${ }^{2}$ Associate Professor, Discipline of English, Digital Humanities and Publishing Studies \\ Research Group, School of Humanities and Social Sciences, Indian Institute of Technology \\ Indore(nmenon@iiti.ac.in)
}

\begin{abstract}
The linguistic setup of Punjab was affected in 1947 partition and mass displacement, that changed the way people engaged with their spoken languages as linguistic identities were increasingly seen in political and national terms. It was mainly during the years of Punjabi Suba movement in the 1950 os in India that was later followed by Indian Punjab's trifurcation in 1966, that identities were projected into two rigid and contrasting categories as Hindi-Hindu and Punjabi-Sikh. Hindu migrants distanced from an ethnic-Punjabi identity towards a projection of an identity as Hindus that was followed by a language shift from native dialects to Hindi. The current generation of Hindu migrants in India, however, is interested in reviving an ethnic-linguistic identity, an identity that is linked to partition migrants' lands and language of origin and one that illustrates an ethnic renewal. Through an analysis of non-fictional testimonies and ethnographic data, we demonstrate ethnic contexts of identity renewal among current generation Hindu migrants. We argue that a movement from 'ethnic amnesia' to ethnic renewal is one instance of a projection of identity that is currently revised to fulfil a collective identity void among partition affected families. The article presents a two-fold case study, one that engages with our respondent's ethnic sentiments and second that engages with ethnic and language activism in community spaces. This paper, thus, elaborates a case of identity formations among current-generation partition migrants in India.
\end{abstract}

Keywords: language gap, project identity, cultural void, ethnic renewal, partition migrants.

\section{Introduction}

The displacement of Hindu migrants from Punjab in 1947 partition and their resettlement in different regions of post-partition India was followed by a shift in their spoken language, from diverse dialects of pre-partition Punjab to Hindi - that was publicised as the national language of India. Linguists pointed out differences in the spoken dialects of British Punjab specifically pointing out the difference between languages of eastern and western Punjab. George A. Grierson (1919) described language of western Punjab as Lahnda in the linguistic survey of India. He writes: "To its east it has Panjabi, spoken in the Central and Eastern Punjab, and it merges so gradually into that form of speech that it is impossible to fix any clear dividing line between the two" (Grierson, 1919). Yet the two have been demonstrated and standardised as two different

(c) AesthetixMS 2019. This Open Access article is published under a Creative Commons Attribution Non-Commercial 4.0 International License (http://creativecommons.org/licenses/by-nc/4.o/), which permits non-commercial re-use, distribution, and reproduction in any medium, provided the original work is properly cited. For citation use the DOI. For commercial re-use, please contact editor@rupkatha.com. 
languages, namely Siraiki ${ }^{i}$ and Punjabi, after the division of Punjab. The linguistic setup of Punjab was affected in 1947 partition and mass displacement of people changed the way people engaged with their spoken languages as linguistic identities started to be increasingly seen in political and national terms. During the years of Punjabi Suba movement in India in the 1950s that was later followed by Punjab's trifurcation in 1966, Hindu migrants from western Punjab were distanced from their Punjabi linguistic identity. The current generation of Hindu migrants in India, however, is interested in reviving an ethnic-linguistic identity, an identity that is linked to partition migrants' lands and language of origin and one that illustrates an ethnic renewal.

Through an analysis of non-fictional testimonies and ethnographic data, we demonstrate ethnic contexts of identity renewal among current generation Hindu migrants. We argue that a movement from 'ethnic amnesia' is currently revised to fulfil a collective identity void among partition affected families. It is likely that language shift from native language to Hindi may have happened in other ethnic groups affected by partition but current ethnic-based identity revisions among Hindu migrants of Punjab puts forth an interesting case of second and third-generation's experience of partition concerning identity.

\section{1 "Ethnic Amnesia"}

Contrary to Bengali and Sikh Punjabi migrants of 1947 partition, Hindu migrants of Punjab could not sustain an ethnic-linguistic identity. There are numerous explanations of this delinking ranging from: Hindu-Sikh dispute in the years of Punjabi Suba movement, active involvement of organisations such as Rashtriya Swayamsevak Sangh and primarily to migrants' displacement from western Punjab that disintegrated a socio-cultural space that could not be replicated. These developments for Hindu migrants of Punjab were followed by a shift in migrants spoken language, from regional dialects to Hindi. On the other hand, Sikh migrants in Punjab accelerated the movement to form a political linguistic identity as speakers of Punjabi, demanding a separate linguistic state in India. For Hindu migrants, however, "identification with the Indian state (became) deeper" which was fundamentally demonstrated through a shift to "Hindu/Hindi identity" (Kaur, 2007). Hindu-Sikh dispute from this period was followed by a language gap that played a major role in Hindu migrants' delinking from a Punjabi identity. Ravinder Kaur describes in her book Since 1947 that in the quest between the right-wing campaign on the one hand and the demand for a separate Sikh state on the other, "language became the prime indicator of Hindu or Sikh identity: Hindus were those who spoke Hindi while Sikh spoke Punjabi” (222). It appeared in this period that linguistic identity markers had replaced religious identity markers of the Partition period. Language became the central metaphor in politics of identity and Hindu migrants of Punjab formed a collective identity by 'forgetting' one language identity for another as Rita Kothari notes “...language-making and unmaking involves both remembering and forgetting”. Hindu migrants' acculturation into a Hindi-Hindu space went alongside an ethnic forgetting that reflected 'essence of a nation (which) is that all individuals have many things in common and also that they have forgotten many things" (Renan, quoted in Kothari). But as Brass, Daiya, Kothari et all note both language and religion continued to be the symbols of communal identities in postcolonial India of which 1984 is a frightening reminder.

The long-term outcome of these developments in the 1950s for the Hindu migrants of Punjab was that they were distanced from their native identities and witnessed a language gap. An ethnic identity linked to native land, villages and cities that were now in Pakistan and a language identity linked to the land of Punjab, was gradually erased in a process to assume a Hindu/Indian 
identity. While these political changes shaped migrants' identity preferences, for an ordinary migrant the politics of identity was not the primary concern in the traumatic period that followed partition. Instead, there was a general earnestness of an immediate resettlement to overcome the loses of partition and to also showcase a resistance against their representation as refugees, something that migrants often found stigmatic. Thus, in the given political and religious circumstances, a shift away from native identities was not simply an opportunistic assimilation into the mainstream as citizens of India but in a way only available mode of assimilation. Although partition migration was atypical in terms of its scale and circumstances, unlike common migration patterns, its migrants did go through assimilation as their geographical, linguistic and cultural spaces were forcibly shifted.

In this paper, we showcase that after two generations of "ethnic amnesia" and language gap in Hindu migrants of Punjab, there is a resurgence of interest in forming an ethnic identity and reviving predecessors' native language. Current generation's interest in ethnic and pre-partition history is displayed through the spaces of community associations and language activism. The interest in an ethnic identity, as we discuss below, is non-political and is principally based in local community associations. The ethnic interest at local community level is displayed through formation of social groups that employ terminologies based on names of partition generation's villages or provinces. Social organizations named as Bahawalpuri samaj or Multani samaj have increasingly flourished in a few cities of northern and central states of India. There are active organizations in Sri Ganganagar (Rajasthan), Mahendergarh (Haryana), Narnaul (Haryana), Nabha (Punjab), Patiala (Punjab), Gwalior (Madhya Pradesh), Mumbai (Maharashtra), Dhulia (Maharashtra) and Delhi that are working in collaboration.

\section{2 "Project identity" and "Ethnic renewal": The case of 1947 Partition Migrants}

Manuel Castells work on identity formations presents a comprehensive account of how individuals and groups make sense of their reality through articulation and assertion of identity. He delineates three forms and origins of identity building in his book The Power of Identity (1997) which he names as Legitimising identity, Resistance identity and Project identity. The third form of identity building that is "Project identity" is a useful definition for our emphasis on collective identity assertions in this study. He defines Project identity as "when social actors on the basis of whichever cultural material are available to them, build a new identity that redefines their position in society, and, by so doing, seek the transformation of overall social structure." This definition can be adapted to understand the nature of identity formations during 1947 partition where redefinition of positions was complex and social transformation was at the cost of social unity and millions of lives. In the current case study, we demonstrate that there are 'social actors' as Hindu migrants of Punjab who seek to redefine their position in society after almost six decades by projecting forgotten native identities but at the level of local community and not seeking any political transformation. Projection of certain identities in this group are towards what Paul Brass calls an "objectively distinct" ethnic group who does not attach "political significance to that fact" or seek to transform their surrounding with an ethnic-political movement. It is rather an "ethnic renewal" that Joane Nagel describes as "the reconstruction of one's ethnic identity by reclaiming a discarded identity, replacing or amending an identity in an existing ethnic identity repertoire, or filling a personal ethnic void" (947). The current ethnic renewal among Hindu migrants of Punjab illustrates filling of a collective 'ethnic void' that we discuss in section below. 
Formation of communal identities during 1947 partition exemplifies how identities were projected as fixed categories against one another in political and national discourses creating conditions of hostility. Partition of India in 1947 or the events in post-partition India such as Indian Punjab's trifurcation in 1966, or the riots of 1984 employed language and religion as markers of group identity that competed with each other as rigid formations. We particularly mention these two events of the post-partition period, Punjab's trifurcation and 1984 riots, due to their serious implication on Hindu-Sikh relation and projection of Hindi-Hindu and Punjabi-Sikh identity in post-colonial India. Current identity projections among Hindu migrants of Punjab as illustrated in our case study challenge these rigid identity formations.

\section{Methodology}

The paper is divided into two main sections. Through an engagement with the data gathered from informal interviews and small talks (Driessen and Jansen), the first section looks at two types of social organizations that are active in Sri Ganganagar and discusses their ethnic interest through a graphical representation of respondent's responses. The second section critically examines ethnic activism within the community in Sri Ganganagar that is filled with cultural and language metaphors. Through a two-fold case study, one that looks at current-generations' interest in ethnic renewal and second that engages with ethnic activism/the work of social organizations and language activists to renew an ethnicity, this paper is an enquiry into current identity formations among present-generation partition migrants in India.

\section{Data}

The data in oral history and ethnography for the current study is mainly gathered from Sri Ganganagar district in Rajasthan and some from Delhi. Sri Ganganagar became the first choice of location because of authors' interest in recording and documenting this region's partition history. More than half of the population of the city (not including villages and towns that are part of the district) consists of families of migrants (mainly from Bahawalpur and Multan) whose experiences of displacement, rehabilitation and struggles have not been documented in any scholarship. Our study is mainly based on our conversations with partition migrants and their families, and responses received from the members of social groups and organisations within the community that are trying to build a distinct identity by reconnecting with their predecessors' past. We conducted deep interviews with 45 partition witnesses and 5 informal interviews with community members from current generation in Sri Ganganagar. Along with the interviews, we tried to understand emergence and outreach of ethnic interest within the community through small talks with witnesses' family members and recorded responses of 135 respondents about their identity and language preferences.

\section{Ethnic interest among current generation partition migrants: A case study of Sri Ganganagar district in Rajasthan}

We asked a few questions from current generation of partition migrants in Sri Ganganagar regarding their identity and language. Their responses point towards an increasing interest in forming an ethnicity. People in the community are increasingly associating with migrants' ethniclinguistic history and are talking about their original villages, languages and cultural practises. 'Bahawalpuri' as an identity category that takes its name from the birthplace of migrants (i.e. 
5 Ethnic Renewal: Identity Formations among Current Generation Hindu Migrants of Punjab of 1947 Partition

Bahawalpur) has become a crucial identity category within existing identity repertoire. The illustration of data in the first graph below (Figure 1) clarifies that numerous identity categories are widespread and both Punjabi and Bahawalpuri are significant identity categories within the current identity accumulation. It is interesting to note an acquaintance with Punjabi identity given the language gap that we discussed in introductory section. The data shows that assertion of Bahawalpuri identity has primarily become prominent and hold considerable symbolic value for an ethnic formation in the district.

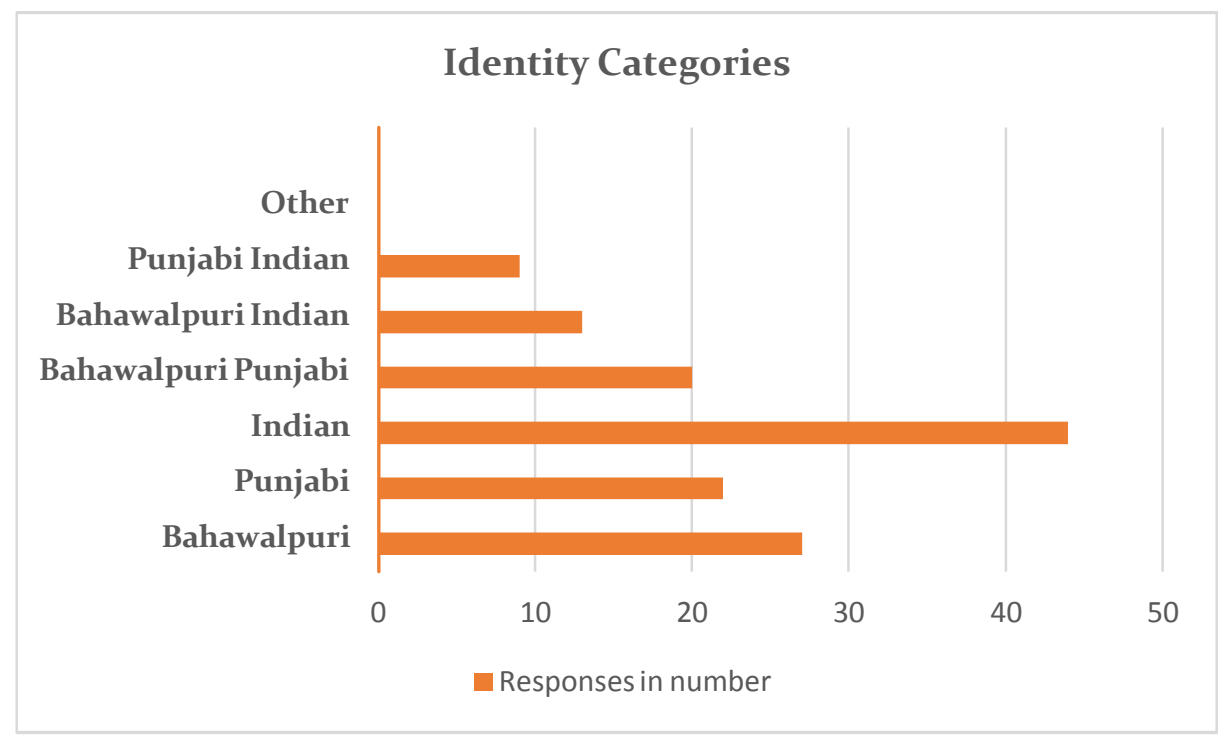

Figure 1: Identity Categories

* The 'other' category includes 'Rajasthani' and 'Rajasthani Indian' but no one associated with these categories.

* These particular identity categories were selected after an analyses of interview transcripts of 45 partition migrants.

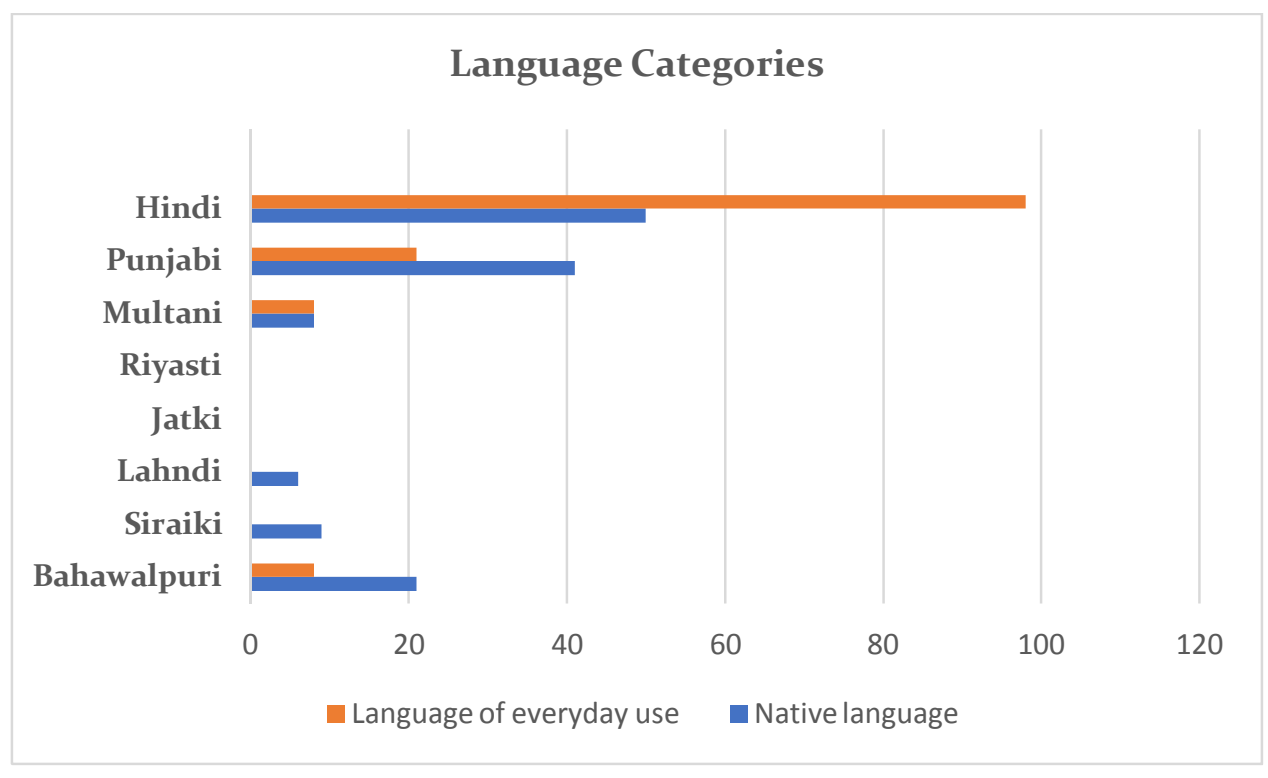

Figure 2: Language Categories 
The graph in figure 2 represents 135 respondent's selection of two separate language categories of 'primary spoken language' and 'native language'. It demonstrates two patterns of language identification among our respondents. First, the difference between language of everyday usage and native language for each language category points towards the shift from native language to Hindi as the spoken language. Second, it demonstrates that Punjabi, Bahawalpuri and other language categories except Hindi are selected as native languages but their usage is significantly lower in comparison. For Hindi, the number of speakers is higher but is not considered as a native language by those many speakers who have clearly selected other language categories as native language. This illustrates that even though native language is selected for projection of an identity but consists of much less speakers in comparison to Hindi.

Many in the current-generation migrants in Sri Ganganagar speak Punjabi as it is spoken in Punjab (different from dialects of Western Punjab (Bahawalpur, Multan et all). Sri Ganganagar is the top-most district on the map of Rajasthan, at the north-eastern part of the state that shares its border with Punjab. Thus, given the geographical proximity with Punjab (that was eastern part of undivided Punjab) and mutual intelligibility of dialects in Punjab, it is highly probable that dialects of Eastern and Western Punjab may have mixed in Sri Ganganagar. The graph illustrates such complex language identities in Sri Ganganagar.

The following quotes ${ }^{\mathrm{iii}}$ from two of our interviewees from the second-generation further illustrate a sense of ethnic void and their desire to demonstrate Bahawalpuri ethnicity.

Bhagwandas Taneja (age: in 5os): My children cannot speak our ma-boli (mother tongue). I cannot also speak in Bahawalpuri properly. We used to feel ashamed of our history, of our traditions and languages. Our samaj is now trying to break the stereotypes so that we can really accept who we really are. We want our youngsters to know and accept our history. ${ }^{\text {iv }}$

Arjun Rajpal (age: in 50s): My father is very fond of Urdu language. He is well read in Urdu (language of primary education in British Punjab) and still speaks in his native language (Bahawalpuri/Jatti/Riyasti). Although I cannot speak in Bahawalpuri but my son has learned the language from my father and speaks perfectly. As part of Bahawalpuri Samaj we are trying to create an awareness about our origins. We have started to conduct Amarlal Sai puja as a community event that was previously forgotten by many in our community. ${ }^{v}$

A notion of both historical embarrassment as well as a need to recreate a story of origin, of native places and a pre-partition history becomes prominent in these comments and conversations with migrant community. Based on the data represented in the two graphs above and comments of our interviewees we conclude a few focal points on the current status of ethnic interest in the community:

1. The language lag between second and current generation has led to an interest in knowing predecessors' native history, a cultural-linguistic history of the community.

2. Siraiki ethnic identity in Pakistan's Punjab is a reminder of their ethnic amnesia.

3. Lack of a native/primary spoken language unlike other co-existing caste-based communities such as jats and Baniyas or ethnic groups such as marwaris. Each of these other groups have a 'native' language apart from Hindi.

4. There's an absence of a language identity in an absence of 'native' language

5. There is a collective desire to connect to their ancestral roots especially in a situation where those places are difficult to access, both geographically and culturally.

6. A collective desire to form a community identity in local spaces that is not necessarily politically motivated. 
In the following section we demonstrate current ethnic interest among current generation migrants through an engagement with ethnographic data on community activism.

\section{Coming from a cultural void: ethnicity and project identity}

\subsection{Two Types of Community Organizations among Hindu migrants from Punjab}

There are principally two kinds of community organizations among the migrant community in Sri Ganganagar that provide the context for defining the shape and status of the community identity. The first type is the caste-based association known as 'Arorvansh', a large group that seeks voluntary participation from the families of primarily two castes Arora and Khatri who formed the majority of Hindu migrant population from Punjab in 1947. The caste based social associations are not uncommon in India which serve as constant sources of sustaining a sense of distinctive identity in local spaces. Aroras in Punjab were mainly shopkeepers and traders and Khatris were the wealthiest landowning and business class of Punjab. There was clear difference mainly that of social status between Aroras and Khatris in Punjab. Two groups, however, have gradually merged as one caste community post their arbitrary rehabilitation by the state in the years following partition displacement. They are now generally considered as one individual caste-group as where the mutual differences have blurred.

The second kind of community organization, in Sri Ganganagar and many other towns mainly in north and central India (as mentioned above), is an ethnic-based group known as Bahawalpur samaj. The formation of ethnic-based organizations among current generation Hindu partition migrants of Punjab is a recent development, only a decade old. Bahawalpur samaj was formed in 2008 with an aim of reviving awareness about community's forgotten pre-partition history. It was formed as a sister organization to Arorvansh. A majority of Hindu migrants from Bahawalpur and Multan in Punjab belonged to these two castes of Aroras and Khatris and Bahawalpur Samaj was formed as a separate organization to reflect and work upon community's ethnic interests. Bahawalpur Samaj in Sri Ganganagar works in collaboration with its other branches in northern towns, for example, in Mahendergarh (Haryana), Narnaul (Haryana), Nabha (Punjab), Patiala (Punjab), Gwalior (Madhya Pradesh), Mumbai (Maharashtra), Dhulia (Maharashtra) and Delhi.

\subsection{Organization activity in Sri Ganganagar}

Bhagwandas Taneja also talks about community activism: "the primary occupation of Bahawalpur samaj in Sri Ganganagar is to gather families with partition history on a single platform to create awareness regarding formation of an ethnicity." Bahawalpur samaj organises community meetings where members talk about the absence of an identity and memory discourse linked to their predecessors' partition and pre-partition history. One of the chief agendas of these meetings is to create awareness about their predecessor's native history, mainly their mother tongues that were forgotten in the post-partition period. The association in Sri Ganganagar in collaboration with other organisations in different towns organize a community event every year. The venue of the event changes to different towns every year. The event in 2016 that was organized at Bahawalpuri community centre in Delhi attracted a large audience. Academicians, language activists and writers in the community were also present whose speeches called for revival of their mother tongue in the young generation. Bahawalpuri community centre in Delhi has been organising 
annual events or what they call as cultural ceremonies in which members of Bahawalpur samaj across the country participate. The striking element of the event in Delhi was a strong emphasis on reviving the usage of their predecessors' 'ma boli' (mother-tongue).

\subsection{Community events and association with Siraiki}

The event in Delhi is called as Multani/Siraiki samaroh emphasising its support for the Siraiki language sentiments in South Asia. Regions of Bahawalpur and Multan (now in Pakistan) where partition migrants of our study lived also witnessed a language movement in 1950s known as Siraiki language movement. This movement demanded a separate linguistic status for dialects of these regions in Pakistan demonstrating them as a different language from Punjabi. Current ethnic interest in India among Hindu migrants are in some ways related to the Siraiki language movement in Pakistan. The nostalgic impact of ethnic developments in the 'old country' is illustrated in community's responses as quoted above. The Siraiki language movement in Pakistan's Punjab where majority of Hindu migrants lived, earned massive attention as an ethnicpolitical movement in 1960s. Although the political movement gradually faded but it generated ethnic-linguistic sentiments; not just among the Punjabis of the part of Punjab that was named as Siraikistan by the movement activists but the sentiments are increasingly evoked in identity assertions of current-generation of Hindu migrants.

However, the association with Siraiki language movement in Pakistan is sustained mainly in terms of terminologies and symbols and is entirely different in its form and scale. For example, although the term Siraiki was not in use in the regions of Bahawalpur and Multan before partition, third-generation's demonstration of ethnic interests employ Siraiki terminology. Except for the terminology, however, the linguistic revival and ethnic interest among current-generation is careful to not conflate with their larger national and political identity.

Usage of a terminology, whether linked to migrants' places of origin such as Bahawalpur/Multan or to ethnic-linguistic sentiments presently prevalent in those regions, has helped in creating awareness within the community. But more importantly, these terminologies make it easier to project an identity that will be more acceptable within the community mainly in an absence of a direct connection to the lands of origin. Along with the terminology, reference to partition history in the speeches at the meetings are aimed at generating an emotive appeal towards a forgotten history. Devidyal, an 88 years old partition witness, expresses his displeasure in his interview that how many in the younger generation do not even have a knowledge of names of their grandparents' native towns or villages. Thus, a public discourse regarding an absence of an ethnic identity is being created with references to an ethnic-linguistic history that was not carried forward in the post-displacement period.

\subsection{Projecting Identity through social groups: Evoking cultural and language metaphors}

Cultural symbols, historical or current, are important elements in formation of a group identity. "Culture is most closely associated with the issue of meaning. Culture dictates the appropriate and inappropriate content of a particular ethnicity and designates the language, religion and belief system, art, music, dress, traditions, and lifeways that constitute an authentic ethnicity" (Nagel 161). Language and religion, as noted mainly in last one and half century, have become two predominant symbols of communal identity in South Asia. A display of language and religion as distinct cultural and political symbols of identity have caused grave cleavages in northern India 
(Brass). Local community organizations such as Bahawalpuri samaj, however, employ cultural symbols, language or religion, in a careful manner that do not conflate with their larger national and political identity. Cultural meaning among current-generation migrants are generated to fulfil the previous ethnic and language gap. It's one way of re-negotiating their ethnic identity as the community looks at it as a revival but equally aware that an ethnic revival has to be reconciled with their present social identity. Thus, cultural and Language metaphors are invoked as elements of past that can be included in the current identity projection.

For the current generation, migrants' memory and their testimonies are the primary links to access the past or their land of origin which is not easily accessible given the toughened political fence between India and Pakistan. Current generation's memory of the native lands is thus coloured by migrants' memory that has become a source of cultural and language symbols. By accessing the past through snippets of information in migrants' memories, current generation aims to re-negotiate history to serve ethnic and cultural needs of current identity repertoire.

\subsection{Language as cultural metaphor}

"How do we examine language as the thing itself and as a metaphor?"- Rita Kothari

Ravinder Kaur notes in her book... how in a "quest for territorial demarcation and separate identity, language became the prime indicator of Hindu or Sikh identity: Hindus were those who spoke Hindi while Sikhs spoke Punjabi" (222). Hindu migrants from Punjab prioritised a "Hindi/Hindu" identity over their identity as Punjabi. However, the current renewed interest in connecting to the history and formulating an ethnicity through language revival or recalling predecessors' ethnic-linguistic identity is expressed in different terminologies that started to take shape only after partition. Terminology for current renewed ethnicity is derived from titles of partition migrants' old villages/cities, for instance their identity as a Bahawalpuri or Multani than Punjabi. The linguistic sentiments are also linked to Siraiki not Punjabi. Rather than reclaiming a 'Punjabi' ethnicity, current generation ethnic formation borrows terms from Siraiki ethniclinguistic formation in Pakistan, a post-partition ethnic formation of old country.

In Bahawalpuri samaj in Sri Ganganagar, awareness for Siraiki language is created through the organization's bi-monthly periodical that along with news and updates on community related activities also publishes short pieces of literary writings in Siraiki. These periodicals that are widely published and circulated within the community have played an important role in attracting community attention towards the language. While the sentiments to revive a forgotten 'mother tongue' are actively displayed, calling for a language revival would require work on language at the level of literature, academia, documentation and policy. Siraiki language renewal is so far limited to a few literary writings. Apart from the community periodicals that publish literary pieces in Siraiki, a few book-length works have also been published. The Multani: Hindi Shabdkosh by Rana Pratap Singh is a dictionary that translates in 700 pages multiple Multani/Bahawalpuri words into Hindi. Literary and language reference books such as Multani Lok Sahitya aur Sankriti by Hukumchand Rajpal, Siraiki Kahaniya by Malik Rajkumar or Siraiki Lok Virsa by Ramkishan Sharma are chief examples of literature by authors who are also leading figures of Siraiki ethnicity in India.

In ethnic identity projections among current generation migrants in India, however, these literary writings although few are playing a considerable role in reviving a forgotten mother tongue. It needs to be also noted that all literary writings in Siraiki in India are written in 
Devanagari script. The Siraiki enthusiasts in India take pride in historical Siraiki literature especially with works of classical literary figure of Khwaja Ghulam Farid who wrote in PersianArabic. Farid is evoked as a central figure in formation Siraiki ethnicity in Pakistan. However, there is often an ignorance or maybe a fear of relating to a 'Muslim' history among partition migrants in India. There are many among Partition migrants and among second-generation Urdu intelligentsia who are well-versed in Persian-Arabic. Siraiki writings in Devanagari, thus, highlight two different patterns. First, is that language revival attempts are in Devanagari than in PersianArabic script of classic literature in Siraiki. Thus, when seen as a crucial part of ethnic resurgence among current generation does not showcase a movement against previous acculturation and assimilation. Second, it should be pointed out that after the language gap it would be favourable to use Devanagari to create awareness about the language as ordinary current generation migrants might not know Persian-Arabic. Thus, Siraiki in Devanagari seen as a symbol of ethnicidentity renewal is a noteworthy third-generation development.

The following two quotes from two different speakers from the second-generation at the event in Delhi illustrate sentiments towards language gap within the community:

Why are we ashamed of speaking our own language? There is no shame in speaking our mother-tongue... Mother-tongue is our right. ${ }^{v i}$

It is the mistake of our generation. We did not teach Multani/Siraiki to our children. My daughter once said to me..." we are stupid and unlucky that we do not even know our mother-tongue. We cannot speak in our own language. You guys talk among yourselves and we don't understand." We need to teach our kids the language. ${ }^{\text {vii }}$

In the post-partition history of Hindu migrants' engagement with language as practise or as a symbol, it has played a catalyst in making and unmaking of identities. It has been employed as a catalyst of identity shift at a particular historical period or as a source that gives meaning to a new identity. In the current public discourse created around ethnicity in the Bahawalpuri community, the Siraiki language is evoked as a historical cultural symbol for current identity desires. As a cultural symbol of identity, language undergoes "constant transformation". As Hall notes, cultural identity "...is not a fixed origin to which we can make some final and absolute return" (226). The current interest in an ethnicity linked to Siraiki language in India speaks of a history of constant transformation of language based cultural identity, transformed at different periods. Thus, more than as a practice, Siraiki language has become a cultural symbol concerning ethnic renewal.

\subsection{Ethnic display of religious symbols: Jhulelal procession}

A majority of Hindu migrants from Bahawalpur worship Jhulelal, who is regarded as the most revered deity of Sindhi Hindus. Nonetheless, it's a rare known fact that Punjabi Hindus from Bahawalpur also worship Jhulelal, regarded as an incarnation of Hindu deity Varuna who as per the Hindu tradition appeared at the banks of Indus river. Thus, also worshipped as a river god, Jhulelal is portrayed as a bearded deity riding a fish like boat. On the day of Cheti Chand, which is commemorated as the birth day of Jhulelal by Sindhi Hindus, Jhulelal in Baharana Sahib is taken to a nearby river or lake in a procession. Celebrated in the months of July-August it was a popular religious festivity among Hindus of Bahawalpur in British Punjab. The similarities in religious practises of Sindh and Bahawalpur were mainly because of their geographical proximity, connected by Indus river. Bahawalpur in British India was predominantly a Muslim province where Hindus were a minority in numbers. Jhulelal as a deity worshipped by both Hindus and Muslims (Sindhi Muslims know the deity as Sheikh Tahir) was also widely worshipped. 
Although individual families from Bahawalpur in Sri Ganganagar continued celebrating the ceremony, it disappeared as a community practise after Partition migration. One of the primary events organized by Bahawalpur samaj centres across towns in India is the Jhulelal procession. It has become an event that receives participation from a large part of the community. In fact, the group has played a crucial role in reviving the practise of Jhulelal as a community event as it used to be in migrants' native towns and villages. Jhulelal among Bahawalpuri Hindus in Sri Ganganagar is regarded as Varun Devta whose birthday is commemorated mostly in the month of August, of special significance during Sawan. The procession of Jhulelal is taken out by Bahawalpuri Hindus in Sri Ganganagar on the day of full moon in the holy month of Sawan in a boat that is taken to a nearby lake or river. The procession sees a large gathering of people celebrating the occasion with colors, dandiya raas and bhajan-kirtan.

While the organisation of events that evoke ethnic symbols and employ ethnic terminologies based in migrants' native history, the revival of Jhulelal procession as a community event is a crucial development for the Bahawalpuri samaj as a cultural metaphor. The practise along with other smaller events has become a significant cultural source of meaning for community's ethnic desires.

\section{Conclusion}

The current generation is safely distant from the event of partition and displacement that they can now remember it as a historical event and talk about it unaffected by a direct trauma that partition migrants witnessed. After almost six decades of ethnic amnesia and collective forgetting of partition trauma, current generation can look beyond the event toward a pre-partition ethnicity of the 'old country. Renewal of 'native' identity among the community in Sri Ganganagar after the acculturation is crucial in context of partition displacement. Cultural symbols from history are redefined to fulfil a present cultural void and project a revised collective identity that includes elements of past into the present. Thus, instead of challenging the acculturation of post-partition period, history is redesigned to serve current identity assertions. But it is important to note that something as that as writing Siraiki in Devanagari and demonstrating this literature as a cultural symbol illustrates an amalgamation of two discrete identity symbols, Siraiki and Devanagari.

\section{Notes}

${ }^{\mathrm{i}}$ The name Siraiki was given prominence as Shackle notes in his article Siraiki: A Language Movement in Pakistan "to create an awareness of regional linguistic unity previously obscured by the use of undesirable vague terms such as 'Hindki' or 'Jatki' coexisting with various local names such as 'Multani' 'Derewal' (in Dera Ghazi Khan) or 'Riyasti' (in Bahawalpur). Its rapidly increasing currency makes 'Siraiki' a much more useful term than these..."

ii Kaur, Since 1947, 217-245.

${ }^{\text {iii }}$ All interview translations are ours

${ }^{\text {iv }}$ Personal Interview, October 2017.

${ }^{\mathrm{v}}$ Ibid. 
${ }^{\mathrm{vi}}$ This is quoted from the event's video-recording.

${ }^{\text {vii }}$ Ibid.

\section{References}

Appadurai, Arjun (1990). Disjuncture and Difference in the Global Cultural Economy. Theory, Culture \& Society. 7 (2-3): 295-310.

Brass, Paul R (2004). "Elite interests, popular passions, and social power in language politics of India." Ethnic and Racial Studies. 27 (3): 353-375.

Castells, Manuel (2010). The Power of Identity. UK: Wiley-Blackwell.

Daiya, Kavita (2008). Violent Belongings: Partition, Gender and National Culture in Postcolonial India. USA: Temple University Press.

Driessen, H., \& Jansen, W. (2013). THE HARD WORK OF SMALL TALK IN ETHNOGRAPHIC

FIELDWORK. Journal of Anthropological Research,69(2), 249-263. Retrieved from http://www.jstor.org/stable/24393899

Gans, Herbert J. (1979). Symbolic ethnicity: The future of ethnic groups and cultures in America. Ethnic and Racial Studies, 2(1), 1-20.

Grierson, George A. (1919). Linguistic Survey of India Vol. VIII. Part I. Calcutta: Superintendent Government Printing, India.

Hall, Stuart (1994). Cultural Identity and Diaspora. In Patrick William and Laura Chrisman (Eds.), Colonial discourse and post-colonial theory.

JAYARAM, N. (2012). Identity, Community, and Conflict: A Survey of Issues and Analyses. Economic and Political Weekly, 47(38), 44-61. Retrieved from http://www.jstor.org/stable/41720163

Kaur, Ravinder (2007). Since 1947: Partition Narratives among Punjabi Migrants of Delhi. India: Oxford University Press.

Kothari, Rita (2015). Questions in and of language. Nehru Memorial Musuem and Library, 47, 1-28.

Kothari, Rita (2007). The burden of refuge: the Sindhi Hindus of Gujarat. Chennai: Orient Longman.

Nagel, J. (1994). Constructing Ethnicity: Creating and Recreating Ethnic Identity and Culture. Social Problems, 41(1), 152-176. doi:10.2307/3096847

O’Brien, E, \& Wilson, J. (1903). Glossary of The Multani Language. New Delhi: Nirmal Publishers.

Pandey, Gyanendra. 1997. Community and Violence: Recalling Partition. Economic and Political Weekly, 32(32), 2037-2045.

Rao, U. Bhaskar (1967). The Story of Rehabilitation. India: Department of Rehabilitation, Ministry of Labour, Employment and Rehabilitation, Government of India.

Shackle, Christopher (1977). Siraiki: A Language Movement in Pakistan. Modern Asian Studies, 11(3), 379403. 